\title{
Synaptic Activity-Induced Conversion of Intronic to Exonic Sequence in Homer 1 Immediate Early Gene Expression
}

\author{
Daniele Bottai, ${ }^{1}$ John F. Guzowski, ${ }^{2}$ Martin K. Schwarz,, ${ }^{1}$ Shin H. Kang, ${ }^{3}$ Bo Xiao, ${ }^{3}$ Anthony Lanahan, ${ }^{3}$ \\ Paul F. Worley, ${ }^{3}$ and Peter H. Seeburg ${ }^{1}$ \\ 1 Department of Molecular Neurobiology, Max-Planck Institute for Medical Research, 69120 Heidelberg, Germany, \\ ${ }^{2}$ Arizona Research Laboratories, Division of Neural Systems, Memory, and Aging, University of Arizona, Tucson, \\ Arizona 85724-5115, and ${ }^{3}$ Department of Neuroscience, Johns Hopkins University, School of Medicine, Baltimore, \\ Maryland 21205
}

Three Homer genes regulate the activity of metabotropic glutamate receptors mGluR1a and mGluR5 and their coupling to releasable intracellular $\mathrm{Ca}^{2+}$ pools and ion channels. Only the Homer 1 gene evolved bimodal expression of constitutive (Homer 1b and c) and immediate early gene (IEG) products (Homer 1a and Ania 3). The IEG forms compete functionally with the constitutive Homer proteins. The complex expression of the Homer 1 gene, unique for IEGs, focused our attention on the gene organization. In contrast to most IEGs, which have genes that are $<5 \mathrm{~kb}$, the Homer 1 gene was found to span $\sim 100 \mathrm{~kb}$. The constitutive Homer 1b/c forms are encoded by exons 1-10, whereas the IEG forms are encoded by exons 1-5 and parts of intron 5. RNase protection demonstrated a $>10-$ fold activity-dependent increase in mRNA levels exclusively for the IEG forms. Moreover, fluorescent in situ hybridization doc- umented that new primary Homer 1 transcripts are induced in neuronal nuclei within a few minutes after seizure, typical of IEGs, and that Homer 1b-specific exons are excluded from the activity-induced transcripts. Thus, at the resting state of the neurons, the entire gene is constitutively transcribed at low levels to yield Homer $1 \mathrm{~b} / \mathrm{c}$ transcripts. Neuronal activity sharply increases the rate of transcription initiation, with most transcripts now ending within the central intron. These coordinate transcriptional events rapidly convert a constitutive gene to an IEG and regulate the expression of functionally different Homer 1 proteins.

Key words: immediate early gene; induced neuronal activity; activity-dependent switch of intron to exon; alternative splicing; alternative transcriptional termination; RNase protection; fluorescent in situ hybridization
Mammals express three Homer genes with different tissue distribution (Xiao et al., 1998). These genes encode 47-48 kDa proteins that feature an N-terminal Enabled/Vasp homology (EVH1) (Gertler et al., 1996; Beneken et al., 2000) domain of the Ena/VASP protein family (Ponting and Phillips, 1997) and a C-terminal coiled-coil domain and leucine zipper (Kato et al., 1998; Sun et al., 1998; Xiao et al., 1998; Tadokoro et al., 1999) for oligomerization. The EVH1 domain binds a proline-rich motif (PPXXFR) (Tu et al., 1998; Beneken et al., 2000) in key components of synaptic signal transduction pathways for calciuminduced and transmitter-induced calcium release (C/TICR). This motif resides in the metabotropic glutamate receptors mGluR1a and $\mathrm{mGluR5a} / \mathrm{b}$, in ryanodine receptors (RyRs), in inositol triphosphate [Ins(1,4,5)P3] receptors (Tu et al., 1998), and in Shank proteins (Tu et al., 1999) that are part of the NMDA receptor-associated PSD-95 complex (Naisbitt et al., 1999). The EVH1 and self-assembly domains permit Homer proteins to forge a physical link between NMDARs and mGluRs with intra-

Received Aug. 13, 2001; revised Oct. 3, 2001; accepted Oct. 11, 2001

This work was supported, in part, by the German Chemical Society (P.H.S.), National Institute of Drug Abuse Grant DA11742, National Institute on Aging Grant AG09219, National Institute of Mental Health Grant KO2 MH01153 (P.F.W., S.H.K., B.X., A.L.), and US Public Health Service Grant MH60123 (J.F.G.). D.B. was supported in part by a fellowship of the European Commission, and M.K.S. was supported by a European Molecular Biology Organization fellowship. We thank D. Kuhl, E. Krupp, and H. Hiemisch for valuable discussions.

Correspondence should be addressed to Peter H. Seeburg, Department of Molecular Neurobiology, Max-Planck Institute for Medical Research, Jahnstrasse 29, 69120 Heidelberg, Germany. E-mail: seeburg@mpimf-heidelberg.mpg.de Copyright (C) 2001 Society for Neuroscience 0270-6474/01/220167-09\$15.00/0 cellular $\mathrm{Ca}^{2+}$ stores for efficient C/TICR. Homer interaction also regulates spontaneous mGluR1a and mGluR5 activity (Ango et al., 2001), modulates N-type calcium and M-type potassium channels (Kammermeier et al., 2000), and regulates axon pathfinding (Foa et al., 2001) and spine morphology (Sala et al., 2001). Thus Homer proteins play key roles in signal transduction in the brain.

Notably, only the Homer 1 gene, which is predominantly expressed in brain, also gives rise to the immediate early gene (IEG) products Homer 1a and Ania 3 (Brakeman et al., 1997; A. Kato et al., 1997; Berke et al., 1998), which have levels that increase sharply by neuronal activity. Homer 1a and Ania 3, approximately one-half the size of the constitutive Homer proteins, contain the EVH1 domain but lack the oligomerization domain. They differ from each other by a few C-terminal amino acid residues, and their transcripts have unique 3' UTRs (Brakeman et al., 1997; A. Kato et al., 1997; Berke et al., 1998). These short Homer 1 forms compete with the long Homer proteins for binding to signaling components, thus functioning as endogenous dominant-negative regulators of T/CICR (Xiao et al., 2000). They also promote spontaneous mGluR1a and mGluR5 activity (Ango et al., 2001) and enhance modulation of N- and M-type currents (Kammermeier et al., 2000). Hence, the short Homer 1 forms modulate the properties of the long forms and are critically involved in activity-dependent alterations of synaptic structure and function.

Here we investigate the Homer 1 gene organization and address the expression of the IEG forms of Homer 1. We report that in contrast to most other IEGs that are small $(<5 \mathrm{~kb})$ (Lau and 
Nathans, 1991), the mouse Homer 1 gene features 10 exons and extends over $100 \mathrm{~kb}$. Although BDNF, another complex IEG, uses alternative promoters to switch from constitutive to activitydependent expression (Timmusk et al., 1993), a different mechanism operates for Homer 1. All Homer $1 \mathrm{cDNAs}$ are identical in their 5' UTR and open reading frame through the first 450 nucleotides but subsequently diverge. This had led to the inference that the IEG forms Homer 1a and Ania 3, like the constitutive forms Homer $1 \mathrm{~b}$ and $1 \mathrm{c}$, are derived by alternative splicing of a common primary transcript. However, our study indicates that the IEG forms result from transcript termination within the large central intron, leading to use of intronic as exonic sequence. This appears to be a new way to adapt a constitutively expressed gene to function also as IEG.

\section{MATERIALS AND METHODS}

Homer 1 gene structure. We analyzed four different bacterial artificial chromosomes (BACs) (numbers 14226, 14227, 14228, 14229; mouse 129Sv; Genome System Inc., St. Louis, MO) that contain overlapping parts of the mouse Homer 1 gene. They were characterized by restriction mapping, Southern blotting, and DNA sequence analysis. Probes for Southern blots were rat Homer 1a and 1c cDNA fragments encompassing the complete open reading frame of the two transcriptional variants.

Northern blot analysis. Total RNA was extracted with TRI Reagent (Molecular Research Center Inc., Cincinnati, OH) from the forebrains of control and mice that underwent maximal electroconvulsive shock (MECS) treatment (Cole et al., 1990), in accordance with the guidelines of the Johns Hopkins Animal Care and Use Committee. Northern blots were performed as recommended by the manufacturer (Northern-max, Ambion, Austin, TX). In brief, $20 \mu \mathrm{g}$ of total RNA or $3 \mu \mathrm{g}$ of poly $\left(\mathrm{A}^{+}\right)$ RNA was fractionated on $1 \%$ Agarose gel and transferred overnight in the presence of $20 \times \mathrm{SSC}(1 \times \mathrm{SSC}=0.15 \mathrm{M} \mathrm{NaCl}, 0.015 \mathrm{M}$ Na-citrate $)$ onto Bright-Star membrane (Ambion). RNA was UV-cross-linked to membrane, and glyoxal was removed in $10 \mathrm{~mm}$ of Tris- $\mathrm{HCl}, \mathrm{pH} 8$, at $65^{\circ} \mathrm{C}$, followed by a rinse in $5 \times \mathrm{SSC}$. Hybridization was at $42^{\circ} \mathrm{C}$ in ULTRAhyb buffer (Ambion) with $\left[{ }^{32} \mathrm{P}\right] \mathrm{dCTP}$-labeled DNA probes (Random prime kit, Boehringer Mannheim, Mannheim, Germany); specific activity was $10^{8} \mathrm{cpm} / \mu \mathrm{g}$ for Homer 1a (nucleotides 877-2476; see Table 1), Ania 3 [nucleotides 568-1185 and Homer 1b/c transcripts (rat Homer 1c Nsi I-Nsi I fragment, nucleotides 510-2302) (Xiao et al., 1998)]. Membranes were washed at $50^{\circ} \mathrm{C}$ in $0.5 \times$ SSC, $0.5 \%$ SDS, and exposed to $\mathrm{x}$-ray film with intensifier screen overnight at $-70^{\circ} \mathrm{C}$.

RNase protection. Riboprobes for Homer 1a, Homer 1b/c, Ania 3, Homer 1 (pan probe, EVH1), and cyclophilin (internal control) were synthesized from genomic DNA or PCR fragments cloned into pBluescript (Stratagene, La Jolla, CA). To rule out cross-hybridization of the probes with genomic DNA, the total RNA was DNase treated, and the probe contained, contiguous to the exonic sequence, a short tail of intronic sequence that will not be protected. Radiolabeled cRNA probes were transcribed using the Transcription in vitro System (Promega, Madison, WI) in the presence of $\left[{ }^{32} \mathrm{P}\right] \mathrm{CTP}[12 \mu \mathrm{M}$ final (CTP)] to obtain specific activities ranging from $5 \times 10^{8}$ to $1.3 \times 10^{9} \mathrm{cpm} / \mu \mathrm{g}$, whereas the specific activity of the cyclophilin probe was $3-5 \times 10^{7} \mathrm{cpm} / \mu \mathrm{g}$. The Ania 3 probe was 267 bases, 213 of which were protected (944-1161; see Table 1); the Homer 1a probe was 212 bases, 138 of which were protected (nucleotides 4003-4140; see Table 1); the pan EVH1 domain probe was 223 bases, 113 of which were protected (nucleotides 386-498, see Table 1 ); the Homer $1 \mathrm{~b} / \mathrm{c}$ probe was 368 bases, 70 of which were protected (nucleotides 564-633, see Table 1); and the cyclophilin probe was 244 bases, 164 of which were protected. RNase protection was performed with the RPA III Ribonuclease Protection Assay Kit (Ambion). The gel-purified probes were hybridized at the same time with the target RNA for $14 \mathrm{hr}$ at $42^{\circ} \mathrm{C}$. The samples were then digested with RNases A and $\mathrm{T} 1$ for $30-45 \mathrm{~min}$ at $37^{\circ} \mathrm{C}$. Digestion was blocked, and the hybridized RNA was precipitated, washed with $70 \%$ ethanol, dried, and resuspended in $10 \mu \mathrm{l}$ of gel loading buffer, and hybridized radioactivity was determined by scintillation counter. Typically, half of the samples were fractionated on a $5 \%$ polyacrylamide $-8 \mathrm{M}$ urea gel, which was dried and exposed overnight to x-ray film with intensifier screen at $-70^{\circ} \mathrm{C}$. Dried gels were exposed to X-Omat AR film (Eastman Kodak, Rochester, NY) for different lengths of time to obtain linearity for all bands of interest (usually $8 \mathrm{hr}$ for Pan $(\mathrm{EVH})$ probe, $24 \mathrm{hr}$ for Homer 1a, cyclophilin, and
Homer b/c, and $48 \mathrm{hr}$ for Ania 3). The films were scanned (Epson GT-9600, Seiko-Epson Corporation) and analyzed using Image Gauge 3.2 (Fuji). Volume integration of protected radiolabeled bands was corrected for background. Increases in Homer 1 transcripts were averaged from three experiments each with total forebrain RNA $(10 \mu \mathrm{g}$ per hybridization) from control and MECS-treated mice.

$5^{\prime}-R A C E$. Poly $\left(\mathrm{A}^{+}\right)$RNA from MECS-treated mice and two total RNA preparations from control and MECS-treated mice were used to prepare cDNA. RACE was performed with FirstChoice RLM-RACE (Ambion) (Maruyama and Sugano, 1994; Schaefer, 1995). Four different cDNAs were obtained (two independent preparations were from MECS mRNA), and these were analyzed by PCR. Two cycles of nested PCRs were performed with two sets of gene-specific nested primers: GSP1/ NGSP1 and GSP2/NGSP2 [gene-specific primer 1 (GSP1), 5'-TCCCGAGGAGCAGCAGCGGAGCCATTTC-3'; nested gene-specific primer 1 (NGSP1), 5'-GGCCCCCGCCGAGCACAATGGAG-3'; genespecific primer 2 (GSP2), 5'-GCTCGTGCCCCCACCCCGGCTCGTCTCT-3'; nested gene-specific primer 2 (NGSP2), 5'-CTCCCGCTCCGCGCCGCCTCACATTCC-3']. The nine PCR products were gel purified and sequenced directly or were subcloned in pCRTOPO TA cloning vector (Invitrogen, Carlsbad, CA) before individual clones were

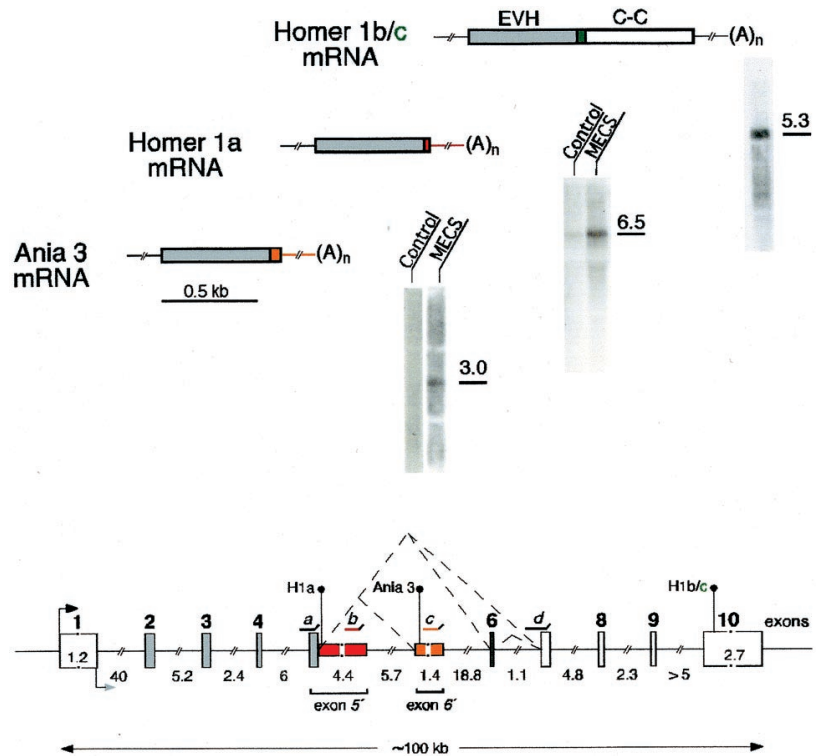

Figure 1. Homer 1 gene and transcripts. The mRNAs encoding Homer 1b/c, Homer 1a, and Ania 3 are depicted schematically next to Northern blots showing these transcripts in brain RNA from naïe (Control) and MECS-stimulated mice (Homer 1b/c, control only). The open reading frames in the mRNAs are boxed and structured by shading and color to show the different functional domains and indicate their origin within the Homer 1 gene shown below. EVH, EVH1 domain, lightly shaded; $C-C$, coiled-coil domain, white box; the alternatively spliced exon 6 for Homer $1 \mathrm{c}$ is shown in green. The intron 5 origin of sequences in Homer 1a and Ania 3 mRNA is indicated by red and orange. The Homer 1 gene encompasses $\sim 100 \mathrm{~kb}$ and is structured into 10 exons, which are boxed and numbered in bold. The exons are drawn to scale (see bar under Ania 3 mRNA), except for exons 1 and 10, for which sizes in kilobases are shown inside the boxes. Shading and color of exons correspond to those in mRNAs. The putative transcriptional initiation site is depicted by a bent arrow at the beginning of exon 1; the translational start at the $3^{\prime}$ end of exon 1 is shown by a lightly shaded arrow. The translational stops for Homer 1a (H1a) and Ania 3 as well as for Homer 1b/c $(H 1 b / c)$ are indicated by black diamonds. Intron sizes in kilobases are listed under the slashed intron line. Intron 5 comprises 30261 nucleotides and is here divided into four segments ( $4.4 \mathrm{~kb}$ of Homer 1a 3' UTR, $5.7 \mathrm{~kb}$ up to Ania 3, $1.4 \mathrm{~kb}$ of Ania 3-specific sequence, and $18.8 \mathrm{~kb}$ to exon 6). The Homer 1a-specific exon $5^{\prime}$ extends exon 5 by intron 5 sequence. The Ania 3 -specific exon $6^{\prime}$ sits within intron 5. The alternative splicing of exon 6 and the activity-dependent splice into Ania 3 sequence within intron 5 are indicated by broken lines. $a-d$, Probes used for RNase protection, with exogenous vector sequences depicted by small upward lines. 


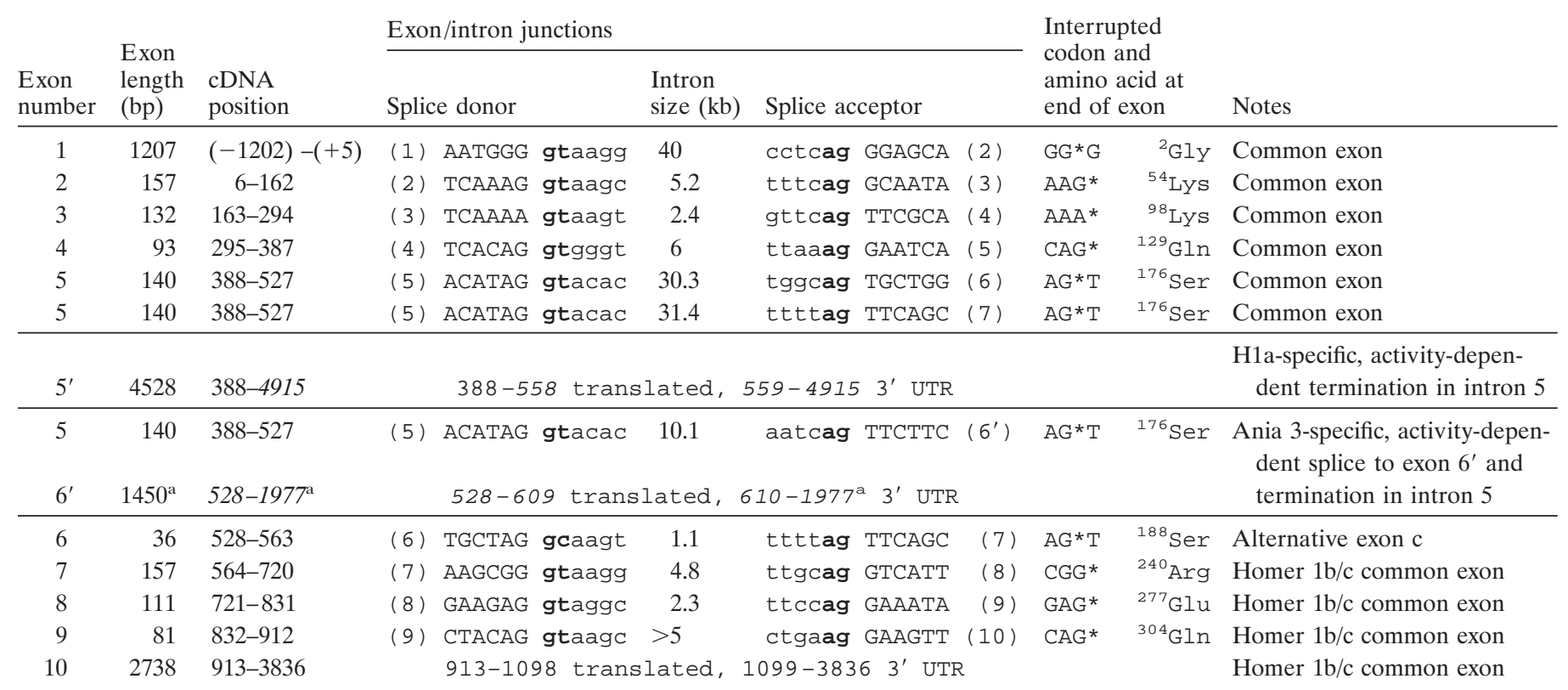

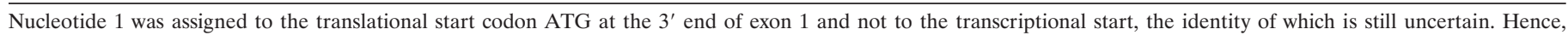

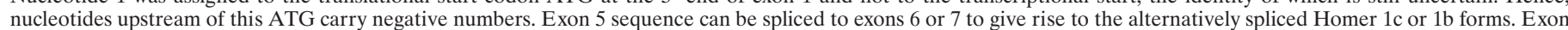

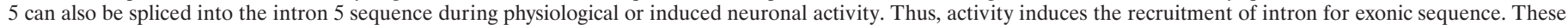

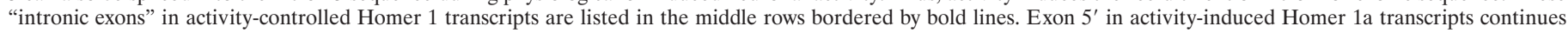

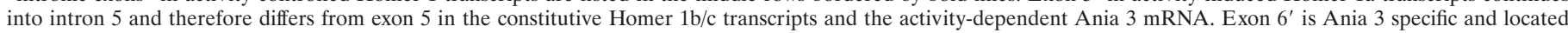

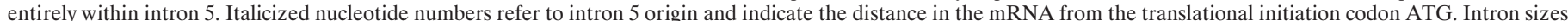

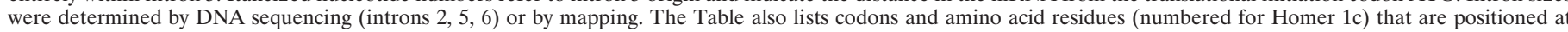
the $3^{\prime}$ end of exons; some codons are interrupted (asterisk) by intronic sequence.

${ }^{a}$ Last nucleotide before poly(A), proposed by sequence inspection on basis of the most probable Proudfoot box, and by RT-PCR analysis (data not shown).

sequenced. Of 23 clones, 14 originated in the vicinity of the $5^{\prime}$ end of the published rat Ania 3 cDNA (Berke et al., 1998).

Fluorescent in situ hybridization. MECS and fluorescent in situ hybridization (FISH) were performed as described (Guzowski et al., 1999). At the appropriate time after handling, adult mice were killed by decapitation using a rodent guillotine. Slices $(20 \mu \mathrm{m})$ were prepared from dissected hippocampi. The time points were $0,5,20,30,40$, and $60 \mathrm{~min}$ after MECS. Hapten-labeled riboprobes were synthesized from either plasmid- or PCR-generated templates using a commercial in vitro transcription kit (MaxiScript, Ambion) and digoxigenin- or fluoresceinlabeling nucleotide mixes (Roche Molecular Biochemicals). For doublelabeling experiments, digoxigenin- and fluorescein-labeled antisense (or sense) probes were hybridized together (100 ng of each probe per slide) and then sequentially detected using Tyramide Signal Amplification (TSA) Direct FISH reagent (NEN Life Science Products, Boston, MA). For all slides, the digoxigenin-labeled probes were detected with cyanine-3 (CY3), fluorescein-labeled probes were detected with cyanine-5 (CY5), and nuclei were counterstained with YOYO-1. The probes were complementary to sequence (for nucleotide numbers, see Table 1) in the $3^{\prime}$ UTRs of Homer 1a (exon 5', nucleotides 4457-4915) and Ania 3 (exon 6', nucleotides 651-1159) mRNAs, to exon 1 (nucleotides -718 to -5 ), to intron 1 (nucleotides 41-813), and to the Homer 1b-specific exons 7-10 (nucleotides 585-1168). Activity-regulated cytoskeleton-associated protein (Arc) FISH was performed as described previously (Guzowski et al., 1999). Fluorescent in situ probes were tested for comparable sensitivity by hybridization to a dilution series of plasmid containing the target sequence. All images were taken at a confocal microscope (Leica TCS-4D, with Krypton-Argon laser and major excitation lines of 488, 568, and $647 \mathrm{~nm}$ ) at an optical thickness of $1 \mu \mathrm{m}$ and were acquired with a $100 \times$ oil immersion objective. The images are located in the granule cell layer of the dentate gyrus. Sense probes for Homer 1a and Ania 3 were used as controls and gave no signals. Additional controls, in which one of the antibody-horseradish peroxidase (HRP) conjugates used to detect a specific riboprobe was excluded, were also performed; these controls are important because the TSA reaction is dependent on HRP for the visualization of both probes.

\section{RESULTS}

\section{Homer 1 gene organization}

The structure of the murine (129Sv) gene for the constitutively expressed Homer $1 \mathrm{~b}$ and 1c proteins, translated from alternatively spliced transcripts that differ in a 36-nucleotide exon unique to Homer 1c mRNA, was characterized by standard procedures, starting from recombinant BACs. The gene organization was obtained by sequencing all exon-containing restriction fragments and by subsequent comparison of the genomic DNA sequences with cognate rat cDNA sequences and consensus splice sites. The open reading frame for the Homer $1 \mathrm{~b} / \mathrm{c}$ proteins is spread over $\sim 100 \mathrm{~kb}$ of genomic DNA and distributed across 10 exons, ranging in size from 36 nucleotides (exon 6, the alternatively spliced "c" exon) to $2.7 \mathrm{~kb}$ (exon 10) (Fig. 1, Table 1. All splice donor and acceptor sites follow the GT-AG rule (Table 1) (Shapiro and Senapathy, 1987), with the exception of the 5' splice site of intron 7, which features a GC dinucleotide instead of the usual GT. A GC dinucleotide as splice donor is extremely rare. The sequence conservation in the immediate vicinity of these rare splice junctions (AG/GCAAG), also observed for intron 7, may reflect the requirement of a special splicing machinery that is involved in crucial gene regulation events (Shapiro and Senapathy, 1987). Exon 1 harbors the 5'-untranslated region and contains the translational initiation codon ATG at its $3^{\prime}$ end. The EVH1 domain, characteristic of all Homor proteins (Beneken et al., 2000), is encoded by exons 2-5, whereas the coiled-coil and leucine zipper domains of the long Homor 1 forms are encoded by exons 6-10. Exon 10 features 186 nucleotides of translated sequence followed by $\sim 2.7 \mathrm{~kb}$ of $3^{\prime}$ UTR. 
Sequence comparison between rat cDNA for Homer 1a (Brakeman et al., 1997; A. Kato et al., 1997) and the mouse Homer 1 gene established that Homer 1a mRNA terminates 4.4 kb into intron 5 (Fig. 1, Table 1). The intronic sequence extends exon 5 by 33 bases (11 codons), followed by a translational stop codon, and a $\sim 4.4 \mathrm{~kb} \mathrm{3'}$ UTR, colinear with the $5^{\prime}$ portion of intron 5. Ania 3, the other known IEG form of Homer 1 (Berke et al., 1998), is generated by alternative transcript splicing from exon 5 into intron 5 sequence that lies $\sim 5.7 \mathrm{~kb}$ downstream of the poly(A) site for Homer 1a mRNA (Fig. 1, Table 1). Inspection of the $30 \mathrm{~kb}$ intron 5 sequence (GenBank accession number AF425674) did not reveal any obvious sequence contribution to the premature transcript termination. In particular, no conserved sequences were found $5^{\prime}$ or $3^{\prime}$ of the poly(A) sites for Homer 1a and Ania 3 transcripts. Comparison with the human intron 5 (data not shown) revealed significant sequence conservation throughout and absence of highly conserved sequence islands that might function in the activity-dependent termination of transcripts within this intron.

We determined the mRNA sizes for the constitutive and activity-dependent Homer 1 mRNAs by Northern analysis of RNA extracted from the brains of naïve mice compared with mice that had undergone MECS treatment. Sizes of 5.3, 6.5, and $3 \mathrm{~kb}$ were seen for Homer 1b/c, 1a, and Ania 3 mRNAs (Fig. 1). Homer 1a transcripts were barely detected in RNA from naïve mice, and Ania 3 transcripts were below detection in this RNA, indicating that MECS dramatically increases the levels of the activity-dependent Homer 1 forms. The Northern signal for Homer $1 \mathrm{~b} / \mathrm{c}$ did not change in intensity with MECS treatment (data not shown; see also below).

\section{Induced neuronal activity boosts Homer 1a and Ania 3 transcript levels}

We used ribonuclease protection assays to quantify the differences in levels of Homer 1 IEG and constitutive transcripts in RNA extracted from the forebrains of mice that had or had not been subjected to MECS (Fig. 2). The results indicate that MECS increased Homer 1a and Ania 3 transcript levels on average by an order of magnitude (Homer 1a, mean \pm SD, $11 \pm$ $1, n=3$; Ania 3, $7.7 \pm 1.5, n=3$ ), whereas Homer 1b/c transcript levels increased only slightly $(1.5 \pm 0.5, n=3)$. Thus, induced neuronal activity leads foremost to an increase in transcript levels for the IEG forms of Homer 1, in concordance with previous in situ hybridization data (Brakeman et al., 1997) and the notion that activity changes Homer protein function (Xiao et al., 1998, 2000). This increase in Homer 1 IEG forms results from de novo synthesis, as reported in cultured cerebellar granule cells (Sato et al., 2001) and determined by in situ visualization of nuclear transcripts in the hippocampus (see below).

\section{TATA-less promoter and multiple transcriptional start sites}

We next investigated the initiation site of Homer 1 gene transcription and searched the presumptive promoter sequence for the presence of motifs that might support the activity-dependent increase in the rate of transcriptional initiation. The sizes of Homer 1a, Homer 1b/c, and Ania 3 mRNAs (Fig. 1) together with the known 3' UTRs and exon sizes predict that transcription starts $\sim 1.2 \mathrm{~kb}$ upstream of the translational initiation codon ATG. Indeed, a rat cDNA clone for Ania 3 contains a 5' UTR of that size (Berke et al., 1998). We therefore determined $2 \mathrm{~kb}$ of sequence upstream of the translational initiation codon (Fig. 3)
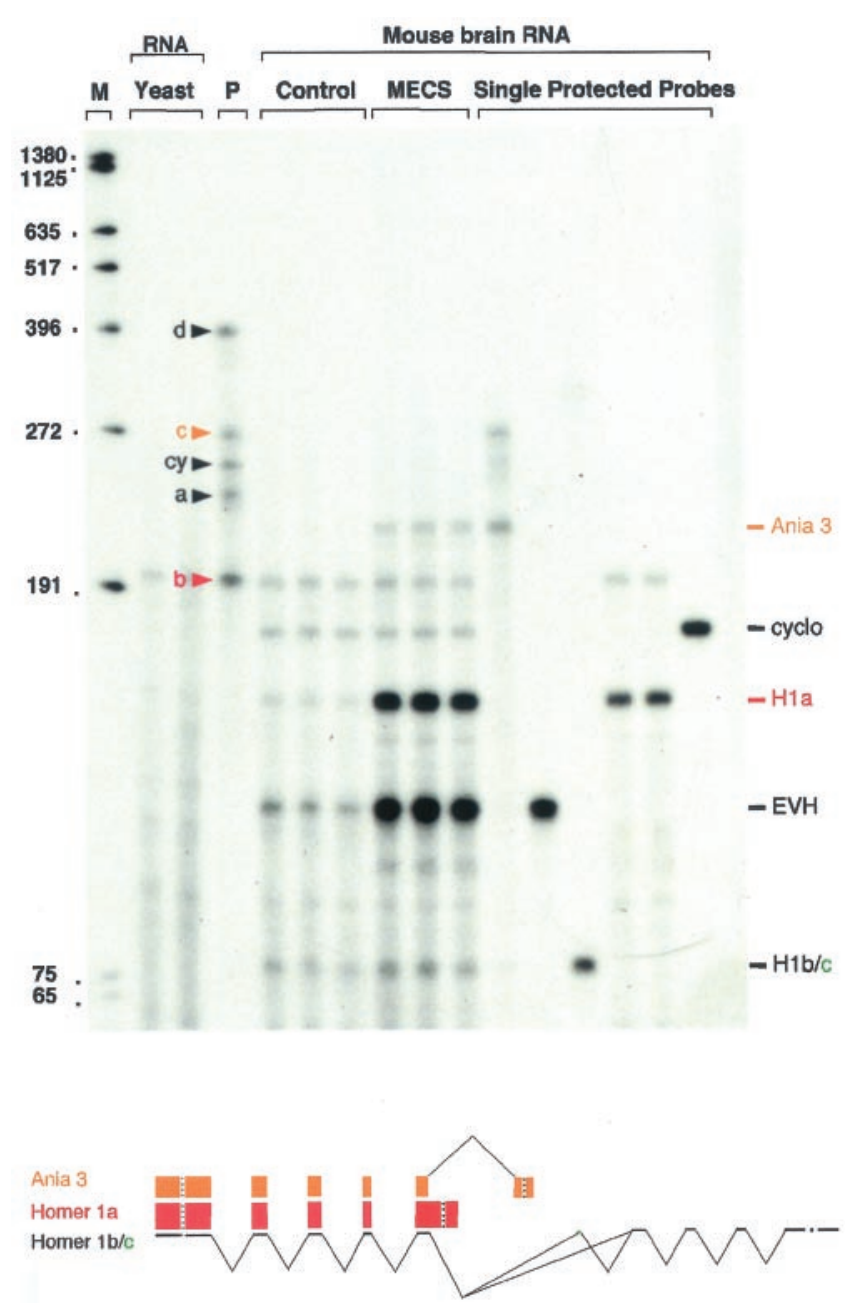

Figure 2. Constitutive and activity-dependent Homer 1 gene transcription assessed by RNase protection. The relative levels of different Homer 1 transcripts in forebrain total RNA from mice treated by MECS and from control mice were determined with a mixture of four RNA probes $(a-d$; see Fig. 1) specific for exon 5 ( $a$, EVH domain common to all Homer 1 forms), Homer 1a 3' UTR (b), Ania $33^{\prime}$ UTR (c), and exon 7 $(d$, specific for Homer $1 \mathrm{~b} / \mathrm{c})$. A probe for cyclophilin $(c y ;$ cyclo $)$ was included as internal standard. Unprotected and protected probes were resolved by gel electrophoresis. $M$ (lane 1), Molecular weight markers with nucleotide lengths indicated on the left. Yeast RNA (lanes 2, 3), No protected fragments. $P$ (lane 4), Unprotected probes. Control (lanes 5-7), RNA in triplicate from control mouse. MECS (lanes 8-10), RNA in triplicate from MECS-treated mouse. Single Protected Probes (lanes 1116), Sizes of the individual protected probes, indicated on the right. Note that small amounts of undigested probes appear in lanes labeled Yeast and Single Protected Probes, but these do not interfere with the protected signals. The results from three RNase protection assays were quantified and summarized graphically by different transcript widths corresponding to averaged increases after MECS of the constitutive and activitydependent Homer 1 transcripts.

and derived several probes for RNase protection. However, these probes were GC-rich and could not be generated at the required amount and integrity (data not shown). We then used 5'-RACE specific for capped RNA (Maruyama and Sugano, 1994; Schaefer, 1995). Results from nine independent analyses yielded several putative transcriptional start sites, most of them in the vicinity of the $5^{\prime}$ end of the published rat Ania 3 cDNA (Berke et al., 1998) (Fig. 3).

The Homer 1 promoter lacks a TATA box and thus might 


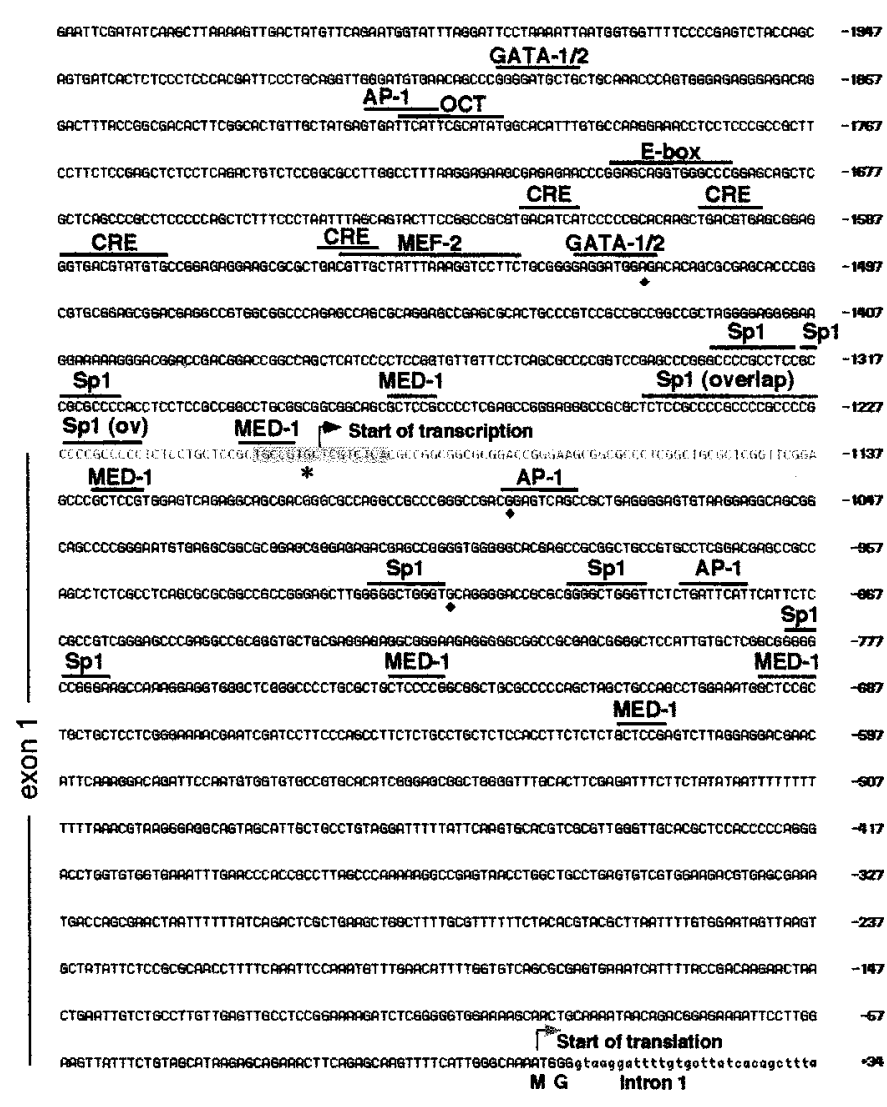

Figure 3. Promoter region, putative transcriptional start sites, and first exon of the mouse Homer 1 gene. Negatively numbered nucleotides are upstream of the first nucleotide (bent shaded arrow) of the translational initiation codon ATG (see also Table 1). Intron 1 nucleotides are in lowercase. Transcriptional start sites determined by $5^{\prime}-\mathrm{RACE}$ are indicated in the sequence. The shaded sequence with the bent arrow represents the region where the majority of RACE fragments had their $5^{\prime}$ ends. This sequence also harbors the $5^{\prime}$ end $(*)$ of Ania $3 \mathrm{cDNA}$ of rat (Berke et al., 1998). The extent of exon 1 based on these start sites is indicated on the left. Other start sites seen less frequently are indicated by black diamonds. Selected cis-acting sequence motifs are overlined.

specify multiple initiation sites (Ince and Scotto, 1995), a notion supported by the presence of several multiple start site element downstream [MED-1 GCTCC $(\mathrm{G} / \mathrm{C})]$ motifs around the experimentally determined transcriptional start sites (Fig. 3). Moreover, the sequence around the putative transcriptional starts features numerous motifs [transcription factor binding sites profile database (Heinemeyer et al., 1998) http://pdap1.trc.rwcp.or.jp/research/db/TFSEARCH.html] that are possibly involved in Homer 1 gene regulation. These include Sp1 (GC-box) (Blake et al., 1990; Kollmar et al., 1994; Suske, 1999), AP1 (Lee et al., 1987), GATA (Evans et al., 1988), octamer recognition site (Parslow et al., 1984), cAMP response element (Montminy et al., 1986), and E-box (Blackwell et al., 1990; Kako and Ishida, 1998) (Fig. 3). The presence of sites for the cAMP responsive elementbinding protein family of transcription factors is indeed expected from the involvement of the mitogen-activated protein kinase in Homer 1a induction (Sato et al., 2001). The Homer 1 promoter lacks the serum response element that is important for induction of c-fos by MAP kinase and p90 ${ }^{\text {rsk }}$ (Edwards, 1994), but it contains instead a similar cis-element, termed MEF-2, that can be activated by serum (Y. Kato et al., 1997).

\section{Fluorescent in situ hybridization reveals new primary Homer 1 transcripts induced by activity}

To visualize the activity-dependent increase in the generation of primary Homer 1 IEG transcripts, we performed FISH in brain sections from MECS-treated mice at different time intervals. We used Homer 1a and Ania 3 antisense riboprobes labeled with different haptens, which were detected with different fluorochromes. The riboprobes detected the cognate $3^{\prime}$ UTRs of the IEG forms in intron 5,>50 kb from the transcriptional start (Fig. 1). No signal was seen in naïve sections; however, 20 min after MECS, punctate fluorescent foci for Homer 1a and Ania 3 appeared in neuronal nuclei, documenting the activity-induced increase in transcriptional initiation of the Homer 1 gene (Fig. $4 A$ ). Nuclei typically contained two adjacent fluorescent foci, consistent with the ability of FISH to detect transcriptional activity at both allelic Homer 1 loci (Guzowski et al., 1999). Furthermore, overlay of Homer 1a- and Ania 3-specific signals indicated the presence of both transcripts at the same foci within a nucleus (Fig. 4A). By 60 min after MECS, the fluorescent in situ signals for the Homer 1 IEG transcripts had spread over the entire nucleus and into the cytoplasm, reflecting transcript processing and nuclear mRNA export. Because of spreading and higher expression of Homer 1a than of Ania 3, the signal overlay at 60 min visualized mostly Homer 1a. Collectively, these results demonstrate de novo Homer 1 gene transcription after induced neuronal activity.

Although the fluorescent signal for the Homer 1a 3' UTR appeared only $20 \mathrm{~min}$ after MECS, induction of Arc was readily detected by $5 \mathrm{~min}$ after MECS (Fig. 4B). Arc is rapidly induced in neurons, coordinately with Homer 1a, in different plasticity paradigms (Lyford et al., 1995), and its time course of induction at intranuclear foci by MECS is similar to that of c-fos and zif268 (Guzowski et al., 1999). The markedly slower appearance of Homer 1 IEG transcripts, as detected by the $3^{\prime}$ UTR probes (Fig. $4 A)$, may reflect the much larger size of the Homer 1 gene $(100$ kb, 10 exons) than Arc (4 kb, 3 exons) (S. H. Kang and P. F. Worley, unpublished observations). Indeed, at in vivo RNA elongation rates of $>2 \mathrm{~kb} / \mathrm{min}$, the $3^{\prime}$ UTRs of the Homer 1 IEG transcripts are not expected to appear in new transcripts before 20 min after MECS. We therefore tested antisense riboprobes close to the transcriptional start (Fig. 1). Both 5' probes for Homer exon 1 and the proximal part of intron 1 attested to an induction of Homer 1 gene transcription that was now as rapid as that of Arc (Fig. 4B). Faster processing of Arc transcripts was indicated by the earlier diffusion of Arc-specific signals from the nucleus (Fig. 4B). The prominent and rapid appearance of the intron 1-specific signal documents that FISH visualizes primary transcripts. Thus, the activity-induced upregulation of Homer 1 RNA results from de novo synthesis, in keeping with its sensitivity to the RNA polymerase inhibitor actinomycin D (Sato et al., 2001). As expected, the signals specific for Homer 1 exon 1 and Homer 1 intron 1 as well as for exon 1 and Homer 1a $3^{\prime}$ UTR were colocalized in nuclei (Fig. 5A-C). The selective loss of the Homer intron 1-specific signal by 60 min after MECS indicates that FISH can be used to track IEG transcript splicing (Figs. 4B, 5B). Coordinate induction of Homer 1 and Arc transcripts in the same cells was also demonstrated by double labeling, but because of different chromosomal localization of these IEGs, their intranuclear foci do not overlap (Fig. 5D). Notably, the Homer 1bspecific riboprobe for exon 7-10 sequences did not detect intranuclear foci (Fig. 5E), even as late as $60 \mathrm{~min}$ after MECS (Fig. 5F), 
A

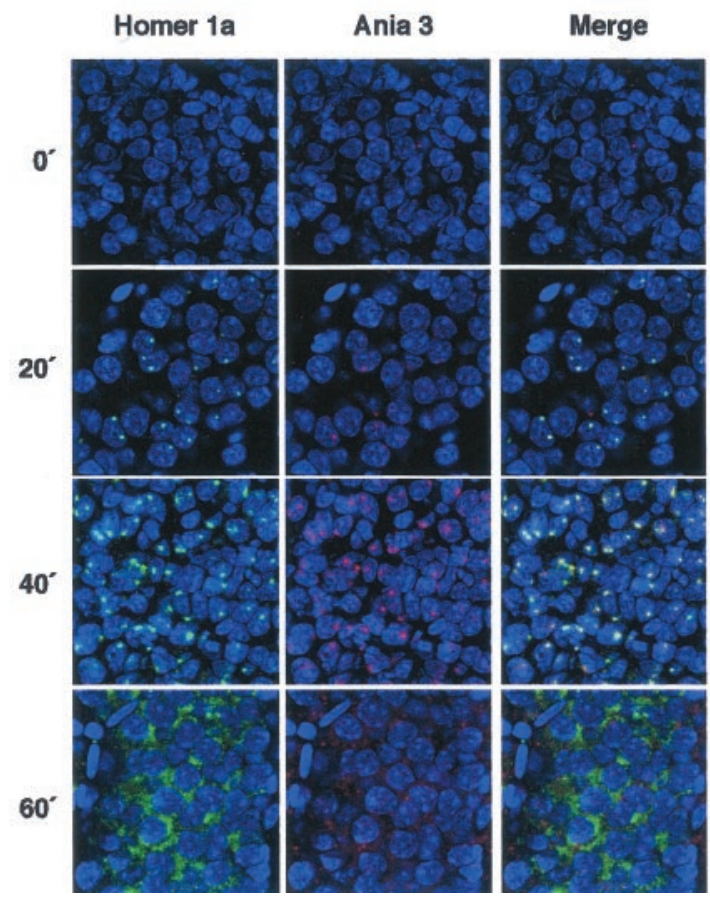

B

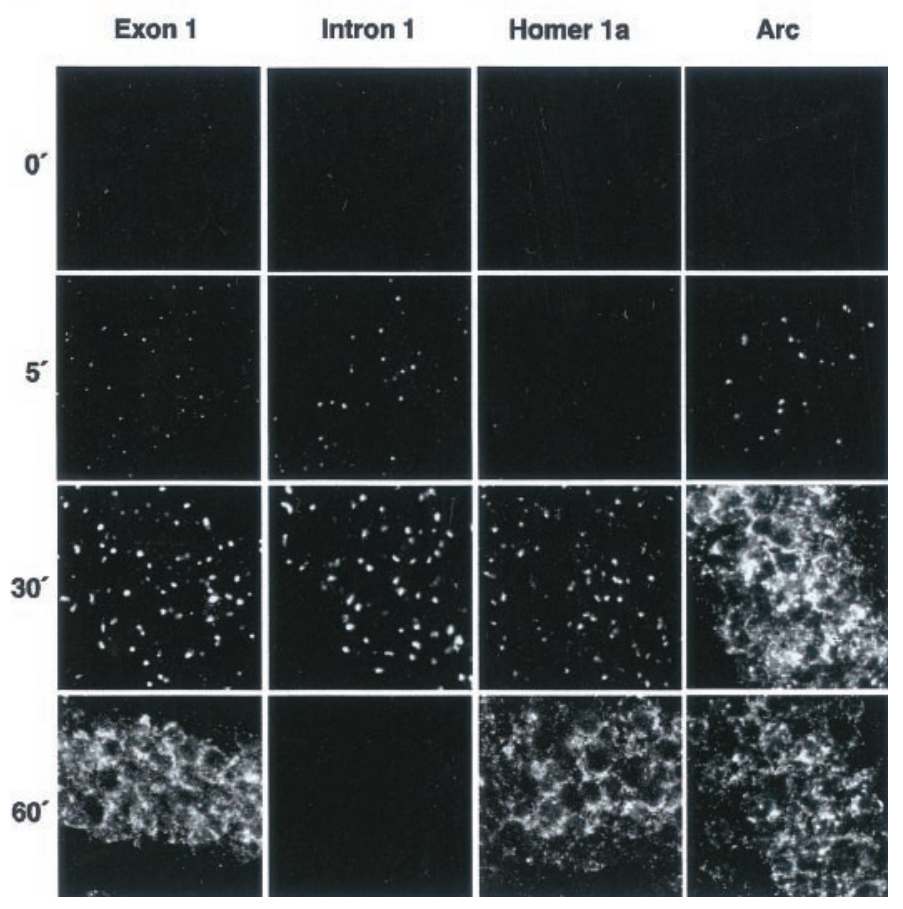

Figure 4. Fluorescent in situ hybridization. A, Time course of induction by MECS of Homer 1a and Ania 3 transcripts in the granule cell layer of the hippocampal dentate gyrus. The Homer 1a probe is detected by CY5 fluorochrome (green), and Ania 3 is detected by CY3 (red). Positionally identical signals become yellow after merging. Nuclei are stained with YOYO-1, here depicted as blue. Homer labeling appears in discrete intranuclear foci 20 min after MECS, indicating sharply increased rates of Homer 1 gene transcription. Some nuclei show two adjacent foci, demonstrating transcription at both Homer 1 alleles. The signals become more diffuse over time because of transcript processing and nuclear export. The higher levels of Homer 1a transcripts and the signal spread prevent the successful merging of Homer 1a and Ania 3 specific signals at 60 min after MECS. B, Time course of induction of the IEGs Arc and Homer after MECS, using for Homer 1 the probes Exon 1, Intron 1, and Homer 1a (3' UTR). Note that the 5' probes reveal comparable induction kinetics for Homer and Arc transcripts, and that the intron 1 signal is lost by 60 min after MECS. Arc-specific signals diff use by the time the Homer 1a 3' UTR sequence becomes visible. All signals are from probe-specific color channels only, converted to gray scale.

when newly synthesized Homer 1a mRNA had already accumulated in the cytoplasm, but faint Homer 1b signals were observed in cells at all times. Thus, the activity-induced Homer 1 gene transcripts appear to terminate before the incorporation of Homer $1 \mathrm{~b} / \mathrm{c}$ exons. However, the slight increase after MECS in Homer 1b/c transcripts, observed by RNase protection (Fig. 2), may indicate that a minority of Homer 1 gene transcripts escape the activity-induced premature transcript polyadenylation/ termination.

\section{DISCUSSION}

\section{Homer gene products}

Three Homer genes encode 47-48 kDa proteins with characteristic EVH1 and coiled-coil domains. Homer proteins play key roles in cell physiological processes, in particular in synaptic function in the brain (see introductory remarks). Homer genes are evolutionarily conserved (Xiao et al., 1998). The EVH1 domains of Homer proteins are $\sim 85 \%$ identical among mouse, rat, and human. Drosophila has a single Homer protein that is $78 \%$ identical in its EVH1 domain to the mammalian orthologs (Xiao et al., 1998). In spite of high sequence conservation, the vertebrate Homer 1 gene alone has evolved to function additionally as an IEG. The IEG proteins Homer 1a and Ania 3 contain the EVH1 domain but lack the domain for self-assembly. As a consequence, the transient Homer 1 IEG forms compete with the larger Homer proteins in the physical coupling of constituents of signaling cascades, interrupting their functional interplay. The
Drosophila Homer gene, only $\sim 4 \mathrm{~kb}$ in size, does not appear to encode a Homer 1a-like protein (Diagana et al., 2002). The unique C-terminal sequence of Homer 1a, encoded by intronic sequence, is identical in 10 of 11 residues among mouse, rat, and human, suggesting that it may confer evolutionarily conserved functions, perhaps related to rapid protein turnover (Ageta et al., 2001). The Ania 3 C termini are not conserved.

\section{Homer 1 gene structure}

The genomic mechanisms involved in the formation of Homer 1a may provide insight into the emergence of a vertebrate IEG within a constitutive gene. These evolutionary aspects and the complex expression of the Homer 1 gene focused our interest on the functional organization of this gene. The Homer 1 gene was found to span $\sim 100 \mathrm{~kb}$ of genomic sequence with 10 exons for the two alternatively spliced constitutive forms. The IEG transcripts end within the large central intron 5 that separates the exons encoding the N-terminal EVH1 domain (exons 1-5) from those encoding the leucine zipper/coiled-coil domain (exons 6-10) of the constitutively expressed Homer $1 \mathrm{~b} / \mathrm{c}$ proteins. Thus the IEG expression unit covers only part of the Homer 1 gene.

\section{Activity-induced transcriptional upregulation and Homer 1 promoter}

Neuronal activity induced by MECS generates a sharp increase in the levels of primary Homer 1 IEG transcripts, as determined here by RNase protection and visualized in nuclei by FISH. FISH 

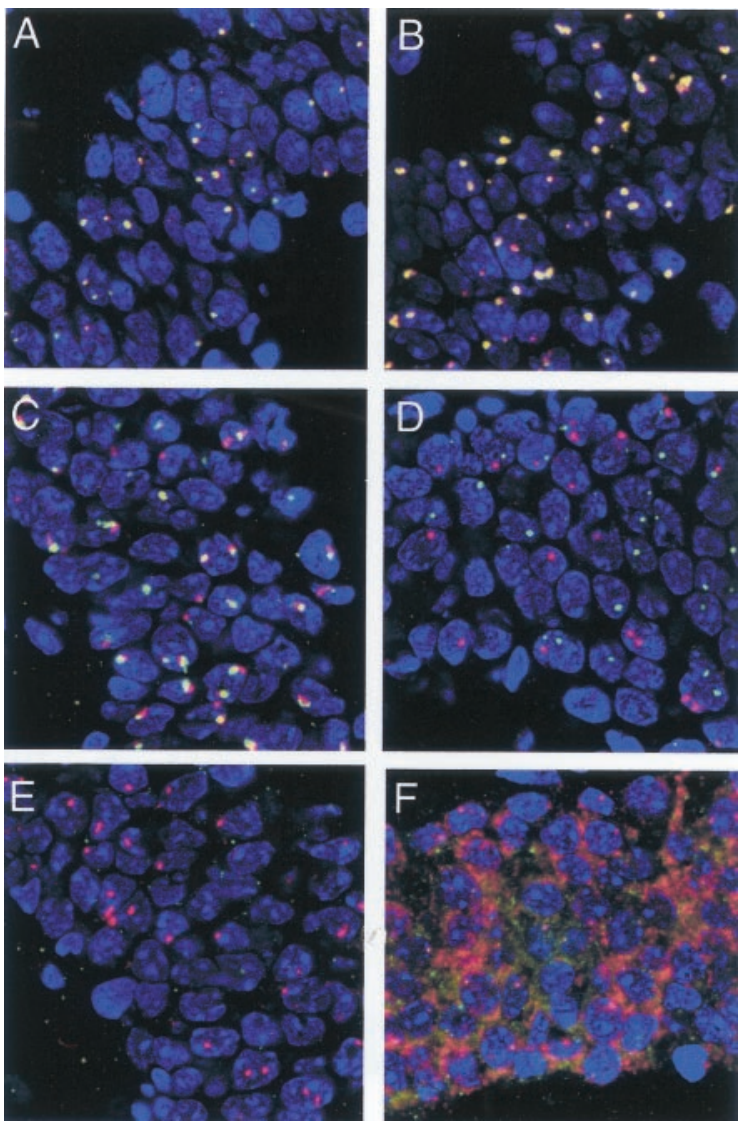

Figure 5. Transcript colocalization by fluorescent in situ hybridization. $A$, Homer 1 exon 1, red channel; Homer 1 intron 1 , green channel; colocalization indicated by yellow; $5 \mathrm{~min}$ after MECS. $B$, Probes as in $A$; 30 min after MECS. $C$, Homer 1 exon 1, red channel; Homer 1a 3' UTR, green channel; 30 min after MECS. D, Arc, red channel; Homer 1 exon 1 , green channel; 5 min after MECS; note that Homer 1 and Arc are activity induced in the same nucleus but appear as separate foci attributable to different chromosomal locations. E, Homer 1a 3' UTR, red channel; Homer 1b, green channel; $30 \mathrm{~min}$ after MECS. F, Probes as in E; $60 \mathrm{~min}$ after MECS. Note that Homer 1a signal has spread from nucleus to cytoplasm without the appearance of Homer 1b-specific intranuclear foci.

also demonstrated that both Homer 1a and Ania 3 transcripts are produced by the same neurons; however, their cellular ratio might be controlled separately. Detection of a MECS-induced intranuclear FISH signal with an intronic riboprobe indicates that the sharp increase in IEG transcripts results from increased transcriptional initiation rates and hence de novo RNA synthesis. Complementary results were obtained by glutamate stimulation of cultured cerebellar granule cells (Sato et al., 2001). The intronspecific signal, but not the exon-specific signals, decayed $30 \mathrm{~min}$ after MECS, consistent with primary transcript processing. The FISH experiments also demonstrate that the time course of Homer IEG induction depends on the position of the riboprobe along the Homer 1 gene. Probes close to the transcriptional start reveal the induction to be as rapid ( $5 \mathrm{~min}$ ) as that of other IEGs induced in brain by MECS (Saffen et al., 1988), including that of Arc. Probes specific for the 3' UTRs of the Homer 1 IEG transcripts yielded signals with considerable delay (20 min), as expected from the time it takes RNA polymerase II to transcribe the $>50 \mathrm{~kb}$ from transcription start to $3^{\prime}$ UTR in intron 5. This situation is reminiscent of the IEG forms of BDNF, which also show slow induction with probes for coding sequence caused by the large gene (Timmusk et al., 1993). Hence, although transcriptional induction is rapid, some IEGs respond slowly with protein because of an extensive transcription unit.

The molecular mechanisms by which activity induces the increased rate of transcriptional initiation have been investigated recently for both the Homer 1 (Sato et al., 2001) and Arc (Waltereit et al., 2001) IEGs. These IEGs are responsive to activitydependent NMDA receptor-mediated $\mathrm{Ca}^{2+}$ influx, and the mitogen-activated protein kinase cascade mediates transcriptional upregulation. In keeping with these commonalities for activity-dependent induction, the time course of induction is comparable for the two IEGs, as shown here by FISH.

Given that the IEG mode of Homer 1 gene expression is stimulus responsive, activity-dependent and constitutive transcripts may initiate from different sites, but no firm evidence has yet been obtained for this notion. Our attempts at delineating transcriptional start sites by 5'-RACE, hampered by GC-rich sequence, yielded preliminary evidence for multiple start sites, mainly from the presence of MED-1 consensus sequences (Ince and Scotto, 1995) in the promoter region. This region also contains numerous cis-acting elements bound by transcription factors, including GC boxes that often determine the rate of transcription initiation (Blake et al., 1990; Kollmar et al., 1994) and could cooperatively induce multiple transcription initiations (Blake et al., 1990).

\section{Homer IEG transcripts terminate within intron 5}

An important observation with respect to MECS-induced Homer $1 \mathrm{IEG}$ expression is that the exon sequence beyond intron 5 was not detectable as intranuclear foci by FISH. Such probes for constitutively expressed portions of Homer 1 detect Homer 1b/c mRNA in neurons, broadly distributed in the cytoplasm of the cell. Detection of inducible intranuclear foci thus provides a powerful tool to assess exon and intron sequences that are transcribed rapidly in response to MECS. Absence of intranuclear signal with probes beyond intron 5 thus indicates that activityinduced Homer 1 transcripts stop prematurely (Uptain et al., 1997) within intron 5, possibly facilitated by alternative poly(A) site selection (Edwalds-Gilbert et al., 1997).

We determined the entire $30 \mathrm{~kb}$ sequence of intron 5 to find clues for sequences involved in the activity-dependent recruitment of intronic sequence. However, inspection of sequences around and beyond the poly(A) sites of Homer 1a and Ania 3 failed to locate any similarities. Moreover, comparison of mouse and human intron 5 sequence (data not shown) did not yield evidence for conserved sequence islands around the $3^{\prime}$ ends of the Homer 1a and Ania 3 transcripts. Hence, the contribution of nucleotide sequence to the generation of the $3^{\prime}$ ends of the Homer 1 IEG transcripts remains unknown. The two IEG forms may differ in function; it is tempting to speculate that Ania 3 evolved as an additional safeguard against elongation of activityinduced transcripts beyond intron 5 .

\section{Coordinate activity-induced transcription initiation and termination}

The activity-induced increase in transcription rate and the termination of the induced transcripts in intron 5 are likely to be coordinated events. A particular initiation site could be functionally coupled to a premature transcriptional termination within intron 5. By distant analogy, an Sp1-like binding site (Suske, 1999) was found in the U1 small nuclear (sn) RNA promoter, the deletion of which impaired transcriptional termination (Hernan- 
dez and Weiner, 1986). Moreover, the $3^{\prime}$ end of these U1 snRNAs is determined by the promoter used (Neuman de Vegvar et al., 1986). Furthermore, an alternative, intronically located poly(A) site resides in the gene for the IgM heavy chain (Edwalds-Gilbert et al., 1997). In this instance, the cleavage stimulation factor subunit 64 (CstF-64) plays a critical role in poly $\left(\mathrm{A}^{+}\right)$site selection (Colgan and Manley, 1997). Little CstF-64 promotes the use of the $3^{\prime} \operatorname{poly}(\mathrm{A})$ site, but increased levels promote use of the weak intronic polyadenylation site, which is located farther 5' (Colgan and Manley, 1997). Because switching Homer 1 gene expression from constitutive to IEG mode does not require de novo protein synthesis, the mechanism should differ from the one operative in $\operatorname{IgM}$ expression and may involve phosphorylation/ dephosphorylation of a factor associated with the transcription machinery.

Indeed, activity-induced Homer 1 gene transcription may be initiated by a complex of RNA polymerase II and assorted transcriptional regulators, which also contains a factor that is activated by phosphorylation and responsible for alternative poly $(\mathrm{A})$ site selection and/or transcription termination within intron 5 . For example, the immunopurified TATA-box binding protein associated factor (TAFIID) contains the cleavage polyadenylation-specific factor (CPSF) (Dantonel et al., 1997) required for the formation of the 3' end of the mRNA (Keller and Minvielle-Sebastia, 1997). After transcription has initiated, CPSF dissociates from TAFIID and associates with the elongating RNA polymerase II (Dantonel et al., 1997), which has a $\mathrm{C}$-terminal region, required for efficient mRNA processing (McCracken et al., 1997), that is highly phosphorylated during the early elongation phase (Uptain et al., 1997).

\section{Conclusion}

Homer 1 is unique among vertebrate Homer genes, and among most IEGs, in having an additional constitutive expression mode. The products resulting from these expression modes differ in sequence and function, and together they regulate the physiology of coupling between mGluRs or ion channels and releasable $\mathrm{Ca}^{2+}$ pools. The switch from constitutive to activity-dependent expression entails intronic to exonic sequence conversion and transcript termination within the central intron of the Homer 1 gene. This predicts the operation of a new mechanism for IEG production, the molecular nature of which remains to be delineated.

\section{REFERENCES}

Ageta H, Kato A, Hatakeyama S, Nakayama K, Isojima Y, Sugiyama H (2001) Regulation of the level of Vesl-1S/Homer-1a proteins by ubiquitin-proteasome proteolytic systems. J Biol Chem 276:15893-15897.

Ango F, Prezeau L, Muller T, Tu JC, Xiao B, Worley PF, Pin JP, Bockaert J, Fagni L (2001) Agonist-independent activation of metabotropic glutamate receptors by the intracellular protein Homer. Nature 411:962-965.

Beneken J, Tu JC, Xiao B, Nuriya M, Yuan JP, Worley PF, Leahy DJ (2000) Structure of the Homer EVH1 domain-peptide complex reveals a new twist in polyproline recognition. Neuron 26:143-154.

Berke JD, Paletzki RF, Aronson GJ, Hyman SE, Gerfen CR (1998) A complex program of striatal gene expression induced by dopaminergic stimulation. J Neurosci 18:5301-5310.

Blackwell TK, Kretzner L, Blackwood EM, Eisenman RN, Weintraub H (1990) Sequence-specific DNA binding by the c-Myc protein. Science 250:1149-1151.

Blake MC, Jambou RC, Swick AG, Kahn JW, Azizkahn JC (1990) Transcriptional initiation is controlled by upstream GC-box interaction in a TATA-less promoter. Mol Cell Biol 10:6632-6641.

Brakeman PR, Lanahan AA, O'Brien R, Roche K, Barnes CA, Huganir RL, Worley PF (1997) Homer: a protein that selectively binds metabotropic glutamate receptors. Nature 386:284-288.
Cole AJ, Abu-Shakra S, Saffen DW, Baraban JM, Worley PF (1990) Rapid rise in transcription factor mRNAs in rat brain after electroshock-induced seizures. J Neurochem 55:1920-1927.

Colgan DF, Manley JL (1997) Mechanism and regulation of mRNA polyadenylation. Genes Dev 11:2755-2766.

Dantonel JC, Murthy KJK, Manley JL, Tora L (1997) Transcription factor TFIID recruits factor CPSF for formation of $3^{\prime}$ end of mRNA. Nature 389:399-402

Diagana TT, Thomas U, Xiao B, Worley PF, Thomas JB (2002) Mutation of iliad, the Drosophila homologue of Homer, disrupts learning during courtship conditioning. J Neurosci, in press.

Edwalds-Gilbert G, Veraldi KL, Milcarek C (1997) Alternative poly(A) site selection in complex transcription units: means to an end? Nucleic Acids Res 25:2547-2561.

Edwards DR (1994) Cell signalling and the control of gene transcription. Trends Pharmacol Sci 15:239-244.

Evans T, Reitman M, Felsenfeld G (1988) An erythrocyte-specific DNAbinding factor recognizes a regulatory sequence common to all chicken globin genes. Proc Natl Acad Sci USA 85:5976-5980.

Foa L, Rajan I, Haas K, Wu GY, Brakeman P, Worley P, Cline H (2001) The scaffold protein, Homer1b/c, regulates axon pathfinding in the central nervous system in vivo. Nat Neurosci 4:499-506.

Gertler FB, Niebuhr K, Reinhard M, Wehland J, Soriano P (1996) Mena, a relative of VASP and Drosophila Enabled, is implicated in the control of microfilament dynamics. Cell 87:227-239.

Guzowski JF, McNaughton BL, Barnes CA, Worley PF (1999) Environment-specific expression of the immediate-early gene Arc in hippocampal neuronal ensembles. Nat Neurosci 2:1120-1124.

Heinemeyer T, Wingender E, Reuter I, Hermjakob H, Kel AE, Kel OV, Ignatieva EV, Ananko EA, Podkolodnaya OA, Kolpakov FA, Podkolodny NL, Kolchanov NA (1998) Databases on transcriptional regulation: TRANSFAC, TRRD, and COMPEL. Nucleic Acids Res $26: 362-367$

Hernandez N, Weiner AM (1986) Formation of the $3^{\prime}$ end of U1 snRNA requires compatible snRNA promoter elements. Cell 47:249-258.

Ince TA, Scotto KW (1995) A conserved downstream element defines a new class of RNA polymerase II promoters. J Biol Chem 270:30249-30252.

Kako K, Ishida N (1998) The role of transcription factors in circadian gene expression. Neurosci Res 31:257-264.

Kammermeier PJ, Bo Xiao B, Tu JC, Worley PF, Ikeda SR (2000) Homer proteins regulate coupling of group I metabotropic glutamate receptors to N-type calcium and M-type potassium channels. J Neurosci 20:7238-7245.

Kato A, Ozawa F, Saitoh Y, Hirai K, Inokuchi K (1997) vesl, a gene encoding VASP/Ena family related protein, is upregulated during seizure, long-term potentiation and synaptogenesis. FEBS Lett 412:183-189.

Kato A, Ozawa F, Saitoh Y, Fukazawa Y, Sugiyama H, Inokuchi K (1998) Novel members of the Vesl/Homer family of PDZ proteins that bind metabotropic glutamate receptors. J Biol Chem 273:23969-23975.

Kato Y, Kravchenko VV, Tapping RI, Han J, Ulevitch RJ, Lee JD (1997) BMK1/ERK5 regulates serum-induced early gene expression through transcription factor MEF2C. EMBO J 16:7054-7066.

Keller W, Minvielle-Sebastia L (1997) A comparison of mammalian and yeast pre-mRNA $3^{\prime}$-end processing. Curr Opin Cell Biol 9:329-336.

Kollmar R, Sukow KA, Sponagle SK, Farnham PJ (1994) Start site selection at the TATA-less carbamoyl-phosphate synthase (glutaminehydrolyzing)/aspartate carbamoyltransferase/dihydroorotase promoter. J Biol Chem 269:2252-2257.

Lau LF, Nathans D (1991) Genes induced by serum growth factors. In: The hormonal control of gene transcription, Vol 6 (Cohen P, Foulkes JG, eds), pp 257-293. Amsterdam: Elsevier.

Lee W, Mitchell P, Tjian R (1987) Purified transcription factor AP-1 interacts with TPA-inducible enhancer elements. Cell 49:741-752.

Lyford GL, Yamagata K, Kaufmann WE, Barnes CA, Sanders LK, Copeland NG, Gilbert DJ, Jenkins NA, Lanahan AA, Worley PF (1995) Arc, a growth factor and activity-regulated gene, encodes a novel cytoskeleton-associated protein that is enriched in neuronal dendrites. Neuron 14:433-445.

Maruyama K, Sugano S (1994) Oligo-capping: a simple method to replace the cap structure of eukaryotic mRNAs with oligoribonucleotides. Gene 138:171-174.

McCracken S, Fong N, Yankulov K, Ballantyne S, Pan G, Greenblatt J, Patterson SD, Wickens M, Bentley DL (1997) The C-terminal domain of RNA polymerase II couples mRNA processing to transcription. Nature 385:357-361.

Montminy MR, Sevarino KA, Wagner JA, Mandel G, Goodman RH (1986) Identification of a cyclic-AMP-responsive element within the rat somatostatin gene. Proc Natl Acad Sci USA 83:6682-6686.

Naisbitt S, Kim E, Tu JC, Xiao B, Sala C, Valtschanoff J, Weinberg RJ, Worley PF, Sheng M (1999) Shank, a novel family of postsynaptic density proteins that binds to the NMDA receptor/PSD-95/GKAP complex and cortactin. Neuron 23:569-582.

Neuman de Vegvar HE, Lund E, Dahlberg JE (1986) 3' end formation 
of U1 snRNA precursors is coupled to transcription from snRNA promoters. Cell 47:259-266.

Parslow TG, Blair DL, Murphy WJ, Granner DK (1984) Structure of the $5^{\prime}$ ends of immunoglobulin genes: a novel conserved sequence. Proc Natl Acad Sci USA 81:2650-2654.

Ponting CP, Phillips C (1997) Identification of homer as a homologue of the Wiskott-Aldrich syndrome protein suggests a receptor-binding function for WH1 domains. J Mol Med 75:769-771.

Saffen DW, Cole AJ, Worley PF, Christy BA, Ryder K, Baraban JM (1988) Convulsant-induced increase in transcription factor messenger RNAs in rat brain. Proc Natl Acad Sci USA 85:7795-7799.

Sala C, Piëch V, Wilson NR, Passafaro M, Liu G, Sheng M (2001) Regulation of dendritic spine morphology and synaptic function by Shank and Homer. Neuron 31:115-130.

Sato M, Suzuki K, Nakanishi S (2001) NMDA receptor stimulation, brain-derived neurotrophic factor upregulate Homer 1a mRNA via the mitogen-activated protein kinase cascade in cultured cerebellar granule cells J Neurosci 21:3797-3805.

Schaefer BC (1995) Revolutions in rapid amplification of cDNA ends: new strategies for polymerase chain reaction cloning of full-length cDNA ends. Anal Biochem 227:255-273.

Shapiro MB, Senapathy P (1987) RNA splice junctions of different classes of eukaryotes: sequence statistics and functional implications in gene expression. Nucleic Acids Res 15:7155-7174.

Sun J, Tadokoro S, Imanaka T, Murakami SD, Nakamura M, Kashiwada K, Ko J, Nishida W, Sobue K (1998) Isolation of PSD-Zip45, a novel Homer/vesl family protein containing leucine zipper motifs, from rat brain. FEBS Lett 437:304-308.

Suske G (1999) The Sp-family of transcription factors. Gene 238: 291-300.
Tadokoro S, Tachibana T, Imanaka T, Nishida W, Sobue K (1999) Involvement of unique leucine-zipper motif of PSD-Zip45 (Homer 1c/vesl- 1L) in group 1 metabotropic glutamate receptor clustering. Proc Natl Acad Sci USA 96:13801-13806.

Timmusk T, Palm K, Metsis M, Reintam T, Paalme V, Saarma M, Persson H (1993) Multiple promoters direct tissue-specific expression of the rat BDNF gene. Neuron 10:475-489.

Tu JC, Xiao B, Yuan JP, Lanahan AA, Leoffert K, Li M, Linden DJ, Worley PF (1998) Homer binds a novel proline-rich motif and links group 1 metabotropic glutamate receptors with IP3 receptors. Neuron $21: 717-726$

Tu JC, Xiao B, Naisbitt S, Yuan JP, Petralia RS, Brakeman P, Doan A, Aakalu VK, Lanahan AA, Sheng M, Worley PF (1999) Coupling of mGluR/Homer and PSD-95 complexes by the Shank family of postsynaptic density proteins. Neuron 23:583-592.

Uptain SM, Kane CM, Chamberlin MJ (1997) Basic mechanisms of transcript elongation and its regulation. Annu Rev Biochem 66:117-172.

Waltereit R, Dammermann B, Wulff P, Scafidi J, Staubli U, Kauselmann G, Bundman M, Kuhl D (2001) Arg3.1/ Arc mRNA induction by $\mathrm{Ca}^{2+}$ and cAMP requires protein kinase $\mathrm{A}$ and mitogen-activated protein kinase/extracellular regulated kinase activation. J Neurosci 21:5484-5493.

Xiao B, Tu JC, Petralia RS, Yuan JP, Doan A, Breder CD, Ruggiero A, Lanahan AA, Wenthold RJ, Worley PF (1998) Homer regulates the association of group 1 metabotropic glutamate receptors with multivalent complexes of homer-related, synaptic proteins. Neuron 21:707-716.

Xiao B, Tu JC, Worley PF (2000) Homer, a link between neural activity and glutamate receptor function. Curr Opin Neurobiol 10:370-374. 